\title{
A BRANQUITUDE DE WHITE FACE AND BLONDE HAIR
}

Rodrigo Severo dos Santos

\section{RESUMO:}

O presente trabalho tem por objetivo analisar a performance White Face And Blonde Hair (2012) da artista multidisciplinar Renata Felinto (1978) a partir do conceito de branquitude (BENTO, 2002; FRANKENBERG, 2004; SCHUCMAN, 2012; CARDOSO, 2017). Na performance, a artista se autorrepresenta como uma mulher loira, sedutora e sorridente para questionar os padrões de beleza branco e ocidental impostos como "universais", e veiculados como naturais pela cultura de massa. O trabalho de Felinto revela como os padrões de beleza que vigoram no Brasil ainda são extremamente eurocêntricos e excludentes estruturando processos contínuos de violência contra às mulheres não brancas e que não estão dentro de um padrão dominante de beleza branca propagado como belo, bom e universal.

PALAVRAS-CHAVE: branquitude, performance negra, corpo negro, artistas afrodiaspóricos, racismo recreativo.

\section{THE WHITENESS OF THE WHITE FACE AND BLONDE HAIR}

\section{ABSTRACT:}

This text aims to analyse the performance White Face And Blonde Hair (2012), by the multidisciplinary artist Renata Felinto (1978) from the perspective of the concept of whiteness (BENTO, 2002; FRANKENBERG, 2004; SCHUCMAN, 2012; CARDOSO, 2017). In the performance, the artist presents herself as a blonde, seductive and cheerful woman to question the white and western beauty standards that are imposed as "universal” and promoted as natural by mass culture. Felinto's work exposes how the beauty standards established in Brazil are extremely Eurocentric and exclusive, structuring continuous processes of violence against women who are not white and who do not match the dominating white beauty standards propagated as beautiful, good and universal.

KEYWORDS: whiteness, black performance, black body, Afrodiasporic artist, recreational 
racism.

\section{A IDENTIDADE BRANCA NO BRASIL}

A branquitude significa a pertença étnico-racial atribuída ao sujeito branco (CARDOSO, 2017), a qual tem sido uma categoria de análise do racismo brasileiro. Pode ser compreendida “como o lugar de conservação, preservação do próprio grupo branco, no lugar onde está, ou seja, no lugar de privilégio” (BENTO, 2002, p. 146). Segundo a psicóloga social Maria Aparecida Bento (2002) a branquitude se caracteriza como território de privilégio racial, econômico e político no qual a racialidade, não nomeada como tal, carregada de valores, de experiências, de identificações afetivas, acaba por definir a sociedade.

Os estudos críticos da branquitude surgem da necessidade de se analisar o papel do grupo racial branco enquanto elemento ativo nas relações raciais, em sociedades estruturadas no contexto de efetivação do projeto moderno de colonização europeia (CARDOSO, 2008; BENTO, 2002; PIZA, 2002; SCHUCMAN, 2012). Esta temática de investigação aponta para a importância de se estudar os brancos com o intuito de compreender o racismo, pois estes sujeitos, intencionalmente ou não, desempenham um papel fundamental na manutenção e legitimação das desigualdades raciais.

Nessa linha interpretativa, Schucman (2012) aponta a branquitude como uma posição. Isto significa que, ao ocupa-la, os sujeitos são sistematicamente privilegiados no que diz respeito ao acesso a recursos materiais e simbólicos, gerados inicialmente pelo colonialismo e pelo imperialismo, e que se mantêm e são preservados na contemporaneidade. Para melhor compreensão sobre o conceito, recorremos a intelectual Ruth Frankenberg (2004 apud SCHUCMAN, 2012, p.30) que apresenta oito elementos que estruturam o conceito de branquitude:

1. A branquitude é um lugar de vantagem estrutural nas sociedades estruturadas na dominação racial.

2. A branquitude é um "ponto de vista”, um lugar a partir do qual nos vemos e vemos os outros e as ordens nacionais e globais.

3. A branquitude é um locus de elaboração de uma gama de práticas e identidades culturais, muitas vezes não marcadas e não denominadas, ou denominadas como nacionais ou "normativas" em vez de especificamente raciais.

4. A branquitude é comumente redenominada ou deslocada dentro das denominações étnicas ou de classe.

5. Muitas vezes a inclusão na categoria branco é uma questão controvertida e, em diferentes épocas e lugares, alguns tipos de branquitude são marcadores de fronteira da própria categoria.

6. Como lugar de privilégio, a branquitude não é absoluta, mas atravessada 
por uma gama de outros eixos de privilégio ou subordinação relativos; estes não apagam nem tornam irrelevante o privilégio racial, mas o modulam ou modificam.

7. A branquitude é produto da história e é uma categoria relacional. Como outras localizações raciais, não tem significado intrínseco, mas apenas significados socialmente construídos. Nessas condições, os significados da branquitude têm camadas complexas e variam localmente e entre os locais; além disso, seus significados podem parecer simultaneamente maleáveis e inflexíveis.

8. O caráter relacional e socialmente construído da branquitude não significa, convém enfatizar, que esse e outros lugares raciais sejam irreais em seus efeitos materiais e discursivos (FRANKENBERG, 2004 apud SCHUCMAN, 2012, p. 30).

O pesquisador Lourenço Cardoso (2008) em O branco “invisível”: um estudo sobre a emergência da branquitude nas pesquisas sobre as relações raciais no Brasil (Período: 1957 2007), sustenta o argumento de que a branquitude enquanto tema nas pesquisas sobre relações raciais no Brasil é uma emergência, destacando que a branquitude na sociedade brasileira "significa ser poder e estar no poder, entre outras coisas” (CARDOSO, 2008, p. 187). Para o autor, a identidade racial do branco, é um lugar de privilégios simbólicos, subjetivos e materiais palpáveis que colaboram para reprodução do preconceito racial, discriminação racial “injusta” e o do racismo.

Vários/as autores/as como Edith Piza (2002), Ruth Frankenberg (1999), Lorenço Cardoso (2008), Lia Vainer Schucman (2012) têm discutido que uma das características da identidade racial branca é a falta de percepção do indivíduo branco como ser racializado, como grupo racializado, ou seja, sua identidade cultural seria expressada enquanto invisível e/ou neutra: “a brancura, neste caso, é vista pelos próprios sujeitos brancos como algo 'natural' e 'normal'” (SCHUCMAN, 2012, p. 24). Ser branco é atribuir identidade aos outros e não ter identidade, pois "não tendo como demarcar sua condição racial, demarcar-se a do ‘outro’ e a não explicitação ou nomeação das razões de uma suposta superioridade confirma o que se verifica cotidianamente. O silêncio sobre sua própria racialidade faz exacerbar a racialidade do outro. A neutralidade torna a raça um dado indispensável. Tornar-se, na verdade, uma porta de vidro. Gera a transparência de um universo que é observado como único, geral, imutável. São os 'outros' que devem mudar. São os 'outros' que devem se aproximar. São os 'outros' que são vistos, avaliados, nomeados, classificados, esquecidos”(PIZA, 2002, 85).

É neste sentido que Edith Piza (2002) diz que os brancos enquanto identidade coletiva são aqueles que não têm a visibilidade da raça: "não se trata, portanto, da invisibilidade da cor, mas da intensa visibilidade da cor e de outros traços fenotípicos aliados a estereótipos sociais e morais para 
uns, e a neutralidade racial para outros. As consequências dessa visibilidade para negros são bem conhecidas, mas a da neutralidade do branco é dada como 'natural', já que ele é o modelo paradigmático de aparência e de condição humana” (PIZA, 2002, p. 72).

Para Cardoso (2008) é impreciso afirmar que o sujeito branco não se reconhece como portador da identidade racial branca porque privilegia o ponto de vista dos brancos, causado pelo olhar imperceptível sobre os seus próprios privilégios, ou seja, o branco não possui autoconsciência e/ou autocrítica racial, logo não têm como questionar suas vantagens raciais.

A ideia de invisibilidade como uma das características principais da branquitude tornou-se objeto de controvérsia na teoria sobre branquitude. Há autores que argumentam nessa direção (WARE, 2004a: 34; FRANKENBERG, 1999b: 70-101; RACHLEFF, 2004: 108), enquanto outros, com os quais partilho a ideia, criticam o argumento de que o branco não se enxerga como grupo racial (FRANKENBERG, 2004: 307-338; WRAY: 2004: 353). [...]. A própria autora Ruth Frankenberg, que sustentava que a invisibilidade era um dos traços significativos da identidade racial branca, acabou por rever sua posição. Agora, sustenta que a invisibilidade como uma característica da branquitude é uma ideia fantasiosa, a concepção de que a identidade racial branca seria uma categoria não marcada não se sustenta. Desde o primeiro encontro dos europeus com os africanos e ameríndios, houve uma delimitação em que portugueses, espanhóis, ingleses, holandeses e alemães foram marcados ou se auto marcaram como brancos. [...]. Matt Wray vai dizer que a definição da branquitude como norma, geralmente seguida pela ideia de que ela é "invisível”, acaba por privilegiar o ponto de vista dos brancos, que sem autoconsciência, não têm como questionar suas vantagens raciais. Esse autor sustentará que a branquitude não é invisível para muitos brancos e serve igualmente para distinguir os brancos entre si, como é caso do branco pobre e do rico" (CARDOSO, 2008, p. 190-191).

O posicionamento de Cardoso também é adotado por Schucman, que a partir dos estudos de Ruth Frankenberg, afirma que a "invisibilidade acontece quando uma sociedade chega ao ponto de uma hegemonia e a uma ideia de supremacia racial branca tão poderosa, em que os não brancos não têm voz nem poder para apontar a identidade racial do branco, nem tampouco os brancos conseguem se perceber como mais uma das identidades raciais, mas sim como a única identidade racial normal, e outras devem alcançá-la em níveis intelectuais, morais, estéticos, econômicos etc..” (SCHUCMAN, 2012, p. 24).

É a partir do sistema invisível/neutro que a branquitude opera de modo estruturante, mantém seus privilégios e institui seu poder ao normatizar padrões sociais que são constantemente reforçados e reproduzidos pela identidade racial branca no Brasil: "não pensar sobre, não refletir 
sobre si e o outro diferente é a regra. A desigualdade é naturalizada, internalizada no cotidiano como o normal. Como perceber o próprio privilégio se o que se chama de privilégio é o que se entende como justo? A desigualdade é a norma” (MIRANDA, 2017, p. 62).

É assim que Maria Aparecida Bento denúncia a existência de uma herança branca da escravidão que foi historicamente silenciada para manter e favorecer os privilégios do grupo racial branco: “[...] há benefícios concretos e simbólicos em se evitar caracterizar o lugar ocupado pelo branco na história do Brasil. Este silêncio e cegueira permitem não prestar contas, não compensar, não indenizar os negros: no final das contas, são interesses econômicos em jogo” (BENTO, 2002, p. 27).

A excessiva visibilidade grupal da identidade negra e a intensa individualização do branco gera o que Edith Piza chama de "lugar de raça”, o qual pode ser definido como “o espaço de visibilidade do outro, enquanto sujeito numa relação, na qual a raça define os termos desta relação” (PIZA, 2002, p.72). Nesta dimensão, “o lugar do negro é o seu grupo como um todo e do branco é o de sua individualidade. Um negro representa todos os negros. Um branco é uma unidade representativa apenas em si mesmo” (PIZA, 2002, p.72).

Vejamos agora como as questões relacionadas a identidade racial branca são tratadas na performance White Face And Blonde Hair (2012) da artista Renata Felinto.

\section{COLOCANDO O BRANCO EM QUESTÃO ${ }^{1}$}

Nascida na cidade de São Paulo (SP), Renata Felinto (1978) é artista visual e professora adjunta de Teoria da Arte da Universidade Regional do Cariri/CE. Doutora, mestra em Artes Visuais, e bacharela em Artes Plásticas pelo Instituto de Artes da Universidade Estadual Paulista Júlio de Mesquita Filho (IA/UNESP), é também licenciada em Artes Plásticas pelo Centro Belas Artes, especialista em Curadoria e Educação em Museus de Arte pelo Museu de Arte Contemporânea da Universidade de São Paulo (MAC/USP). Foi professora de Arte e Cultura Africana no curso de pós-graduação História da Arte: Teoria e Crítica no Centro Belas Artes de São Paulo, coordenadora do Núcleo de Educação do Museu Afro Brasil, integrou o conselho editorial da revista $\mathrm{O}$ Menelick $2^{\circ}$ Ato. A artista tem uma extensa produção artística em diferentes linguagens como instalações, fotografia, pintura e desenho e performances dentre outros, que foram expostas no Brasil e no exterior. Sua produção intersecciona arte, feminino/feminismo e identidade afrodescendente.

1 Este texto integra a pesquisa de doutorado em desenvolvimento no Programa de Pós-graduação em Artes Cênica (PPGAC), na Universidade de São Paulo. 
Os trabalhos artísticos de Felinto foram apresentados em grandes instituições de visibilidade como nas exposições individuais, dentre as quais destacam-se: “Afro Retratos": exposição itinerante pelas unidades do SESI do Estado de São Paulo (São Paulo, 2016); $1^{\circ}$ Mostra Cultural da Mulher Afro, Latino-americana e Caribenha, Centro de Cultura e Formação da Cidade Tiradentes (São Paulo, 2015); Tracker Tower, curadoria Alexandre Araújo Bispo (São Paulo, 2012); “White Face and Blonde Hair”, exposição itinerante pelas unidades do SESI do Estado de São Paulo (2016); “Afro Retratos: A Identidade de Nós”, SESC Carmo, Programação “Estéticas das Periferias”, curadoria Renata Felinto e Antônio Sérgio Moreira (São Paulo, 2014); “Penso, logo resisto”, SESC Bauru (Bauru SP, 2004).

Como também das exposições coletivas: Feira Internacional de Arte Contemporânea curadoria Pascale Óbolo (Paris França, La Colonie, FIAC,2017); “Negros Indícios”, Conjunto Cultural da Caixa, curadoria Roberto Conduru (São Paulo, 2017); “Diálogos Ausentes”, Galpão Bela Maré, curadoria Diane Lima e Rosana Paulino (Rio de Janeiro, 2017; “Uterotopias”, A Mesa Galeria, curadoria Leonardo Bertolossi (Rio de Janeiro, 2017); “Metrópole: Experiência Paulistana”, Estação Pinacoteca, curadoria Tadeu Chiarelli (São Paulo, 2017); “Diálogos Ausentes”, Instituo Itaú Cultural, curadoria Diane Lima e Rosana Paulino (São Paulo, 2016); “Afro como Ascendência, Arte como Procedência”, SESC Pinheiros, curadoria de Alexandre Araújo Bispo (São Paulo, 2013) e “De um lugar no mundo”, Cento e Quatro curadoria de Antônio Sérgio Moreira (Belo Horizonte, 2013).

Em 2012 recebeu o Prêmio Nacional de Expressões Culturais Afro-Brasileiras pelo Ministério da Cultura e pela Fundação Cultural Palmares pelo desenvolvimento da série Afro Retratos e, em 2018 recebeu o Prêmio Clóvis Moura (Fundação Nacional de Artes - FUNARTE) pela Rede Antirracista Quilombação na categoria artes visuais, por contribuição das suas obras no enfrentamento ao racismo. A produção de Renata Felinto entrelaça identidade e gênero, tencionando as construções estéticas e culturais de ambos. Vejamos o que a artista fala sobre sua produção:

Meus trabalhos sempre partiram de meus incômodos, problematizações, constatações, reflexões acerca de mim no mundo, da minha relação com as pessoas, que são os seres mais interessantes que existem no planeta. Cada pessoa como um universo. Entre 2010 e 2011, desliguei-me/desligaram-me de um emprego formal e Afro Retratos surgiu aí. Uma série de pinturas nas quais me desvinculei propositalmente da tradição da pintura produzida no Brasil, me representei como mulher de vários lugares. Foi o pontapé para pensar-me na performance como uma linguagem em diálogo constante com a (minha) vida, com o que pulsa, respira, transpira (FELINTO, 2017, p. 82). 
Na performance White Face And Blonde Hair, que faz parte da série Também Quero Ser Sexy (2012), Renata Felinto se autorrepresenta como uma mulher branca e loira, sedutora e sorridente com ostensiva capacidade de consumo do luxo oferecido na Rua Oscar Freire em São Paulo. Articulando as noções como gênero, raça e classe, Felinto troca as suas referências corporais ao se travestir de mulher branca e com uma peruca loira, usando códigos de vestimenta que lembra uma executiva: joias, óculo escuro, bolsa dentre outros assessórios. O rosto dela está maquiado de forma embranquecida, mas as suas mãos estão na sua cor natural. Com postura altiva, sempre sorridente e extravagante, Felinto caminha por um dos endereços mais nobres da capital paulista e de forte segregação racial, o que nos faz pensar na relação entre corpo negro e espaço público. Assim como o público de alto poder aquisitivo consumidor do local, Felinto olha as vitrines das lojas, entra em algumas delas, realiza compras, entra na cafeteria para degustar um café, ver revistas e observa o movimento dos transeuntes. Falando sobre a performance a artista coloca:

[...] esse trabalho fala de branquitude. É um trabalho que eu pensei a partir justamente de tudo que é branco ou valores sociais que são rapidamente identificados como brancos ou rapidamente pertencentes aos grupos hegemônicos brancos e que não são rapidamente conectados à população negra. [...] o trabalho exalta um padrão de beleza, que é um padrão de beleza de mulher branca que não necessariamente se refere só as mulheres loiras, mas as brancas e até mesmo as negras quando estão dentro de um biótipo[...]. Tem algumas questões naquele trabalho que se refere aos padrões de consumo e de comportamento da branquitude. A gente fala muito no padrão de beleza e esquece às vezes que a branquitude, ela se ancora não só na aparência, mas também em algumas práticas que inclusive negros de classe média quando acendem acabam incorporando como, por exemplo, você sai para passear, mas não sai para ver a rua, para ver as pessoas, para ir a uma biblioteca, a um parque, mas você sai para comprar, para consumir (FELINTO, 2018).

A performance de Renata Felinto coloca uma lente de aumento na intensa invisibilidade da identidade branca, como ser individual e não como ser coletivo, revelando que em uma sociedade racializada, cuja supremacia é branca, não existe invisibilidade e neutralidade em ser branco, mas uma manutenção de privilégios raciais em que as pessoas deste grupo, muitas vezes consciente ou inconscientemente, propagam atitudes racistas que justifica, mantém e reproduz as desigualdades raciais como uma forma de proteger o seu próprio grupo racial dito como “natural”, “padrão” e “norma” enquanto outros grupos aparecem ora como margem, ora como desviantes, ora como inferiores. Pois “mesmo em situação de pobreza, o branco tem o privilégio simbólico da brancura, o que não é pouca coisa” (BENTO, 2002, p. 28). 
O trabalho da artista ativa nosso olhar para entender que o branco não é apenas favorecido nessa estrutura social racializada, mas é também seu produtor ativo através dos mecanismos mais diretos de discriminação e da produção de um discurso que propaga a democracia racial e o branqueamento. Estes mecanismos de produção de desigualdades raciais que foram construídos de tal forma que asseguraram aos brancos a ocupação de posições mais altas na hierarquia social, sem que isso fosse encarado como privilégio de raça (SCHUMAN, 2012).

Renata chama a atenção para o papel que os brancos ocuparam e ocupam na situação de desigualdades raciais no Brasil e denúncia os privilégios simbólicos e materiais que estão postos nessa identidade. E assim como o silêncio e a omissão do branco os protege e os desonera de qualquer responsabilidade, também protege os interesses de seu grupo racial.

Felinto com sua estratégia performativa de travestismo corporal, problematiza a violência racial e como dela se beneficia concreta e simbolicamente os sujeitos brancos ao apontar as consequências dessa visibilidade que leva o negro para a marginalização, discriminação, preconceito, diferenciação, desigualdades dentre outros. Já para os brancos a neutralidade é tida como “natural”, “sujeito universal e essencial” porque ser branco na sociedade brasileira está dentro de um modelo paradigmático de aparência e de condição humano. Aqui como diria o psicanalista Jurandir Costa:

o belo, o bom, o justo e o verdadeiro são brancos. O branco é, foi e continua sendo a manifestação do Espírito, da ideia, da Razão. O branco, a brancura, são os únicos artífices e legítimos herdeiros do progresso e desenvolvimento do homem. Eles são a cultura, a civilização, em uma palavra, a "humanidade” (COSTA, 1984, p. 05).

O Whiteface proposto por Felinto é uma forma de satirizar a branquitude e atacar a ideia racista de superioridade estética com uma hipervalorização silenciosa do branco que nos permite confirmar que estamos diante de valores de beleza e poder construídos historicamente, que começaram com o processo de colonização europeia e que perduram e se reproduzem nos dias atuais (SCHUCMAN, 2012).

Felinto mostra que ser branco vai além do fenótipo porque brancura consiste em ser proprietário de privilégios materiais e simbólicos (CARDOSO, 2017) revelando o lugar do branco numa situação de desigualdade racial presente sociedade brasileira. Em Felinto, assim como dirá a psicólogo social Vainer Schumann,

é preciso pensar o poder da branquitude como princípio da circularidade ou transitoriedade (Foucault, 1999), compreendendo-o como uma rede na qual 
os sujeitos brancos estão conscientes ou inconscientemente exercendo-o em seu cotidiano por meio de pequenas técnicas, procedimentos, fenômenos e mecanismos que constituem efeitos específicos e locais de desigualdades raciais. (SCHUMANN, 2012, p. 23).

Felinto atua nas brechas da branquitude e permite resistir às forças do racismo, que são, no fundo, as forças da violência, do enclausuramento e da exclusão.
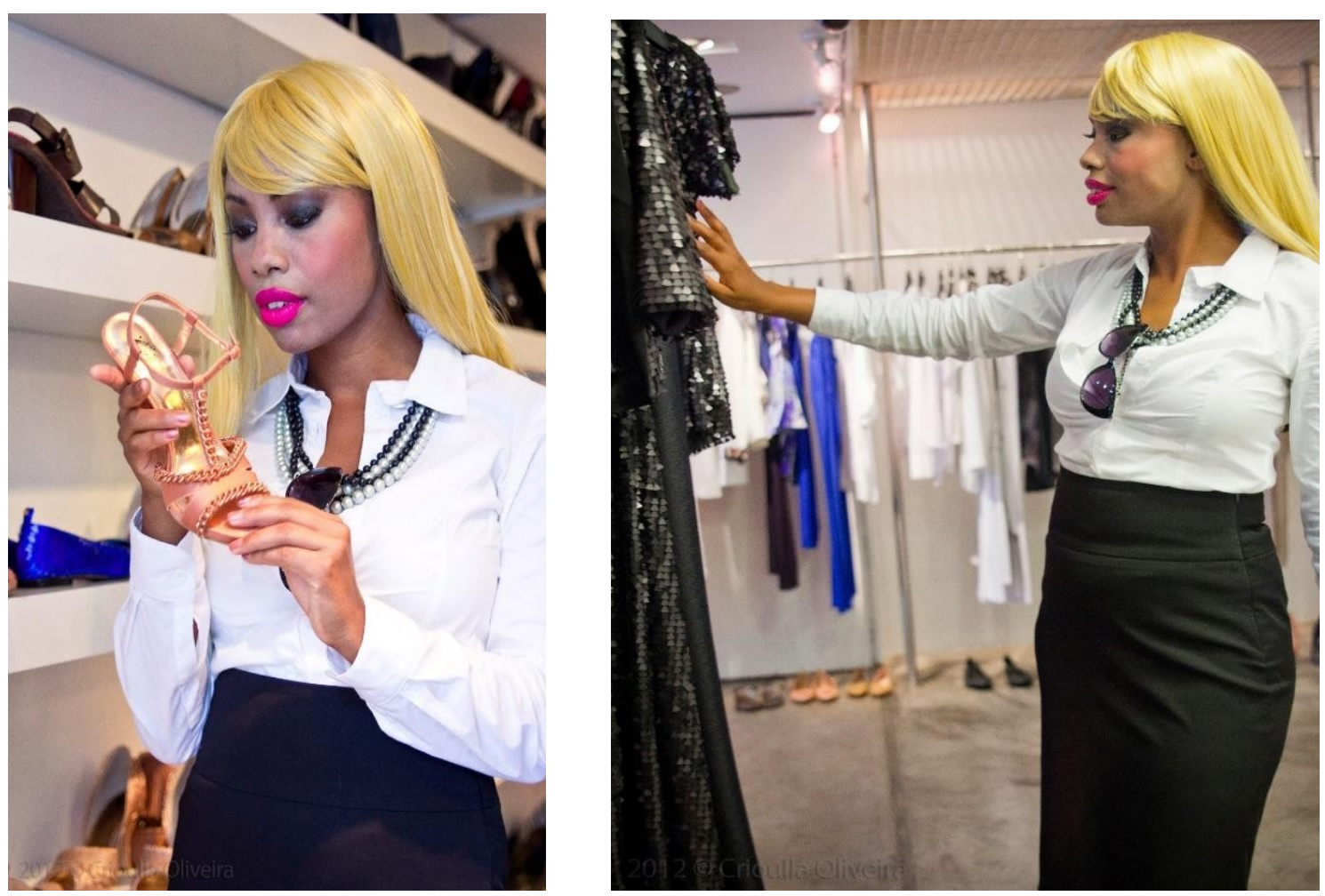

Figura 1: "White Face and Blonde Hair", realizada na Rua Oscar Freire (2012). Foto: Crioulla Oliveira

\section{DA SÁTIRA A DESMORALIZAÇÃO}

Em O que é Racismo Recreativo? (2018) Adilson Moreira ao analisar personagens de programas humorísticos e decisões judiciais em relação ao crime de injúria racial no contexto brasileiro, defende a tese de que o humor racista não possui uma natureza benigna porque ele é um meio de propagação de hostilidade racial. Este tipo de humor para o autor é interpretado como um projeto de dominação racial baseado na noção de inferioridade moral de minorias raciais na qual o grupo racial dominante através de inúmeras representações culturais construídas por pessoas brancas legitima quem merece ou não ser estigmatizado, desprezado, insultado, vilipendiado, 
desmoralizado e desumanizado dentro da cultura brasileira. Definindo o conceito de racismo recreativo o autor destaca:

Esse conceito designa um tipo específico de opressão: a circulação de imagens derrogatórias que expressam desprezo por minorias raciais na forma de humor, fator que compromete o status cultural e o status material dos membros desses grupos. Esse sistema de opressão tem o mesmo objetivo de outras formas de racismo: legitimar hierarquias raciais presentes na sociedade brasileira de forma que oportunidades sociais permaneçam nas mãos de pessoas brancas. Ele contém mecanismos que também estão presentes em outros tipos de racismo, embora tenha uma característica especial: o uso do humor para expressar hostilidade racial, estratégia que permite a operação do racismo, mas que protege a imagem social de pessoas brancas (MOREIRA, 2018, p. 21-22).

Na citação acima, podemos interpretar que o autor trata o racismo recreativo como uma política cultural que utiliza o humor para expressar hostilidade em relação a minorias raciais, hierarquizar grupos raciais e perpetuar a ideia de que apenas membros do grupo racial dominante podem ocupar posições de poder e prestígio. O racismo recreativo opera como um dispositivo de poder e dominação que perpetua o racismo enquanto um sistema de opressão que desqualifica e desmoraliza as minorias raciais ao mesmo tempo em que permite que os membros que compõe a identidade racial branca possam manter uma imagem e uma percepção positiva sobre si mesmo. Dentro deste contexto, as piadas racistas reforçam a superioridade racial branca e a ideia de que as pessoas negras devem permanecer em posições de subalternidades:

Piadas racistas só adquirem sentido dentro de um ambiente cultural marcado pela opressão e discriminação racial; sempre temos a presença de pessoas que são minorias raciais ou que são identificadas por serem membros desses grupos; a violência, o desprezo, a condescendência são parte integrante dessas piadas (MOREIRA, 2018, p.58).

Conforme as ideias de Moreira (2018), o humor racista propaga um discurso de ódio porque ele comunica desprezo em relação às minorias raciais, “expressam um consenso social dos membros do grupo majoritário sobre o valor de pessoas que pertencem a minorias raciais” (MOREIRA, 2018, p.58). Para o autor, piadas racistas é um tipo de mensagem, e assim como todas mensagens expressa valores sociais que não estão desprovidas de sentidos culturais. E neste sentido, piadas racistas refletem a moralidade da sociedade, apontando para quem merece respeito e quem não merece nosso apreço. Como, por exemplo, as piadas feitas com os negros, mulheres, pobres, nordestinos, homossexuais e demais grupos que mostram implicitamente processos de 
marginalização racial e o desprezo que se sentem por grupos ditos minoritários. É sobre as questões no que diz respeito aos estigmas, injúrias e depreciações em relação a população negra que a performance de Felinto se debruça:

White Face And Blonde Hair responde inicialmente a uma permissividade social de se ridicularizar e de fazer da população negra uma eterna caricatura que a gente ver em muitos lugares, no dia-a-dia, nas piadas, nos comentários que na verdade são práticas racistas naturalizadas. Quando você quer falar que uma pessoa não é ninguém chama essa pessoa de negro, quando você quer falar zé povinho, você usa a palavra negro ou a palavra negra como forma de tratamento. O que algumas pessoas vão entender que é um tratamento doce, mas eu entendo como se fosse uma forma de pagamento do sujeito. A pessoa que é sua interlocutora que você chama de negro ou de negra, ela não é ninguém: meu negro e minha negra. Esse trabalho está falando sobre a ridicularização do ser negro, essa caricatura do negro que a gente tem socialmente que coloca as pessoas negras num padrão de negritude criada pelos brancos (FELINTO, 2018).

Se o verdadeiro motivo do humor racista é ridicularizar as minorias raciais, Renata Felinto, utiliza o seu próprio corpo como locus de protesto e reivindicação para responder esteticamente ao racismo recreativo e ao uso racista do procedimento blackface nas produções humorísticas da televisão brasileira. Em entrevista a jornalista Oslaine Silva, a artista afirma:

O problema é que esses personagens, geralmente, estão em programas humorísticos satirizando a população negra a partir de estereótipos que o outro, o branco, colonizador, pessoa num lugar hegemônico, lugar dominante na sociedade imputou a nós negros como se fossem características próprias biologicamente do ser negro. Então, esses personagens usam os recursos como o jeito de andar, de falar, de sorrir no teatro chamado blackface, ou seja, cara preta, que é um tipo de máscara tradicional dessa arte, geralmente satiriza a população negra nos colocando em uma situação ridícula”² (SILVA, 2018, s/p).

No programa humorístico Zorra Total, da Globo no ano de 2012, o ator Rodrigo Sant’Anna interpreta a personagem Adelaide, com recorte de gênero, raça e classe: uma mulher, negra, pobre e feia, que perambula pelos corredores do metrô com seu tablet, pedindo esmolas aos passageiros. O ator para a caracterização de Adelaide usa o recurso do blackface, com o rosto pintado de preto, usa um nariz falso, uma prótese na boca para demonstrar que não tem os dentes da frente, uma peruca

2 SILVA, Oslaine. Mostra fotográfica coloca em discussão padrão de beleza. O Imparcial. 27 de fevereiro 2018. Disponível em: http://imparcial.com.br/noticias/mostra-fotografica-coloca-em-discussao-padrao-de-beleza, 18557. Acesso em: 20/12/2018. 
de cabelos crespos despenteado e como indumentária usa roupas velhas. A personagem traz vários estereótipos negativos que ridiculariza e desvaloriza ainda mais a mulher negra em nossa sociedade. O texto dramatúrgico falado pela personagem denota um baixo domínio da norma culta, reforçando o estereótipo preconceituoso de que as pessoas pobres e negras não dominam este código linguístico. A personagem contracenava com atores e atrizes em sua maioria brancos que riem dela, o que mostra nas lentes racista o lugar social do negro e a superioridade do branco em relação a condição socioeconômica da população negra.

O personagem também era construído a reforçar a superioridade moral de pessoas brancas de classes superiores porque ela representava vários elementos que ao longo do tempo vem sendo considerados como pessoas inferiores: impureza moral associado à pobreza e a degradação moral como produto da condição racial (MOREIRA, 2018, p. 76-77).

O quadro humorístico foi criticado e retirado do ar. Protestos de personalidades como o rapper Emicida: “deixo aqui meu desprezo a este 'humorista' que se aproveita da triste situação em que esta sociedade doente colocou nossas mães/irmãs/esposas/amigas. E maior ainda é minha tristeza com nossos irmãos pretos/brancos/índios que não conseguem identificar tamanha violência racial adentrando suas casas” (MORAIS, 2012, s/p). Diversas ONGs e espectadores denunciaram o programa à Ouvidoria Nacional da Igualdade Racial, da Secretaria de Políticas de Promoção da Igualdade Racial da Presidência da República, sob a alegação de que o personagem apresenta “estereótipos racistas":

[...]o personagem Adelaide do Zorra Total não é humor. Trata-se de alguma coisa criada por mentes racistas que utiliza um conjunto de estereótipo historicamente construído pela sociedade brasileira para representar negros e negras. Isto fica claro no dialeto e nas interações sugeridas pelos quadros exibidos. Um personagem feminino caótico, confuso em suas estórias familiares, tendo como contradição o acesso à tecnologia e sua condição de pobre e negro” (MARTINS, 2012).

A performance de Felinto é uma resposta a exclusão moral, desvalorização e a desqualificação sistemática de minorias raciais pelo uso do blackface e do humor racista: os excluídos moralmente são considerados sem valor, indignos e, portanto, passíveis de serem prejudicados ou explorados. A exclusão moral pode assumir formas severas, como o genocídio; ou mais brandas, como a discriminação (BENTO, 2002). Ao mesmo tempo em que permite que as pessoas brancas mantenham uma representação positiva sobre si mesmas ao encobrir a hostilidade racial por meio do artificio do humor (MOREIRA, 2018). 


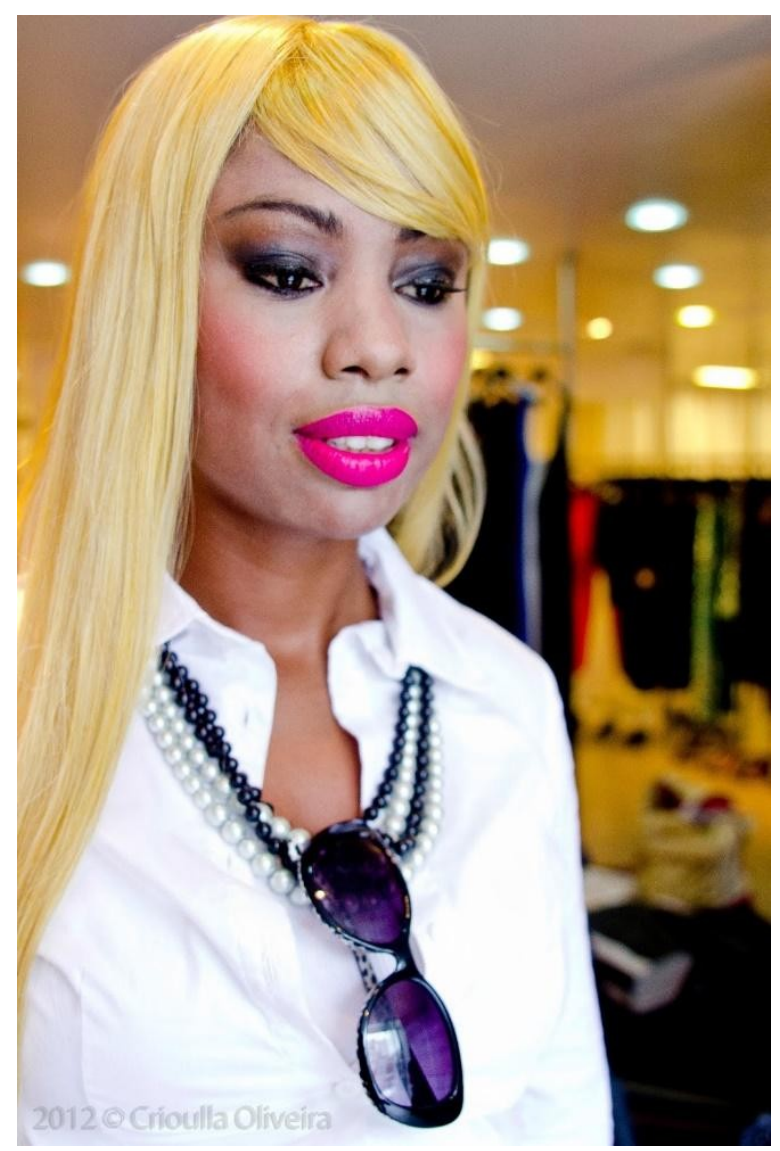

Figura 2: "White Face, and Blonde Hair", realizada na Rua Oscar Freire (2012). Foto: Crioulla Oliveira

\section{DA BELEZA E DO CONSUMO A CRÍTICA}

Em se tratando sobre padrões de beleza e branquitude, Schucman (2012), coloca que a concepção estética e subjetiva construída diariamente acerca da branquitude é, em nossa sociedade, supervalorizada em relação às identidades raciais não brancas. Schucman, em sua pesquisa de campo, ao analisar as entrevistar e as conversar com sujeitos paulistanos que se auto identificaram como brancos, de diferentes classes sociais, idade e sexo, colocará a categoria de "superioridade estética” como um dos traços fundamentais da construção da branquitude no Brasil: “a estética da branquitude é valorizada não apenas por ser mais uma das diversas estéticas disponíveis em nossa sociedade, mas sim por ser aquela significada como a 'verdade' do belo, e que estabelece uma hierarquia em relação aos não brancos” (SCHUCMAN, 2012, p.71).

Sabemos que o colonialismo associou o branco sempre ao "sublime” e o negro ao “execrável”. (FAUSTINO, 2015). No padrão de beleza ocidental a ideia de belo está associada a pertença racial branca e ao definir o que é belo implica necessariamente em definir também o que é feiura e neste jogo relacional: “ o Branco representa a bondade e o Negro, a maldade; o Branco é a 
beleza e o Negro, é a feiura; o Branco é a humanidade, razão e desenvolvimento e o Negro, a natureza e o atraso; o Branco é o sujeito e o Negro, mero 'objeto em meio a outros objetos'” (FANON, 2008 apud FAUSTINO, 2017, p. 130). Ter este padrão de beleza no Brasil “significa pensar que cabelos lisos, pele clara, olhos claros e traços afinados façam parte do modelo vigente de beleza em corpos humanos (SCHUCMAN, 2012).

Em seu livro O que é empoderamento? (2018), a escritora, feminista negra, arquiteta e urbanista, Joice Berth nos orientada que

é fundamental para o processo de luta no campo da estética que fique evidente que toda essa construção negativa da imagem da pessoa negra não teve outra motivação senão sociopolítica. A inferiorização da aparência e da estética negra em detrimento da branca, foi tão somente uma das tecnologias empregadas para sustentar e justificar o sistema de opressão e exploração de sujeitos para o acúmulo de privilégios sociais” [...] (BETH, 2018, p. 100).

É exatamente na perspectiva de quebrar esse sistema de dominação alienador com sua eficácia secular que a performance de Felinto se insere. Ela performatiza o corpo da mulher branca dentro de um biótipo específico. É tomando os sinais diacríticos da identidade racial branca e ridicularizando-os que a artista evidencia as políticas de exclusão fenotípicas que estão naturalizadas na sociedade brasileira.

Felinto ataca justamente a hegemonia estética da raça branca com seu padrão de consumo, nos revelando uma herança branca do período escravocrata com sua falaciosa superioridade narcisista que só leva a processos de exclusão, discriminação e desigualdade racial de pessoas não brancas e que não segue a estas características fenotipicamente:

tanto este traço de superioridade estética quanto o padrão de beleza de nossa cultura não é algo natural ou dado aos brancos. Mesmo assim, essa imagem de belo produz significados compartilhados, dos quais os sujeitos se apropriam, singularizam, produzem sentidos e atuam sobre eles, de alguma forma reproduzindo-os ou contrapondo-os” (SCHUMAN, 2012, p. 71).

Dentro desta lógica, a pesquisadora Liv Sovik diz que "ser branco no Brasil é ter a pele relativamente clara, funcionando como uma espécie de senha visual e silenciosa para entrar em lugares de acesso restrito” (2005, p. 171). É sobre o signo da branquitude que Felinto entrar nos lugares mais caros da cidade de São Paulo para impor sua brancura como sinal de protesto e revelar as relações raciais no Brasil, cuja característica principal seria uma falta de conflito aberto e a convivência pacífica de sofrimento e gozo (SOVIK, 2005).

Felinto ao atuar na dimensão subjetiva do racismo e da branquitude leva-nos refletir sobre 
a ideia normativa que naturaliza o branco como "universal” (CARDOSO, 2008), bem como sobre os padrões de beleza feminino normativo branco e ocidental imposto "universalmente" a todas as mulheres não brancas, que reflete nos lugares que devem ser ocupados por negros e brancos dentro de uma sociedade estruturada pelo racismo.

Se o pesquisador Jorge Hilton de Assis Miranda (2017), ao partir do termo habitus de Bourdieu definiu branquitude como, "habitus racial”, uma faceta do racismo, "um sistema de pensamentos e comportamentos condicionados, individuais e coletivos, que outorga duradouros privilégios - simbólicos e materiais- para as pessoas de fenótipo branco” (2017, p. 65), Felinto nos revela a opressão racial da branquitude com os seus privilégios raciais sustentado pelo mito falacioso da democracia racial como máscara do racismo que só beneficia os privilégios da brancura no Brasil, que “ao longo da história do país, vem servindo ao triste papel de favorecer e legitimar a discriminação racial (BENTO, 2002, p. 48).

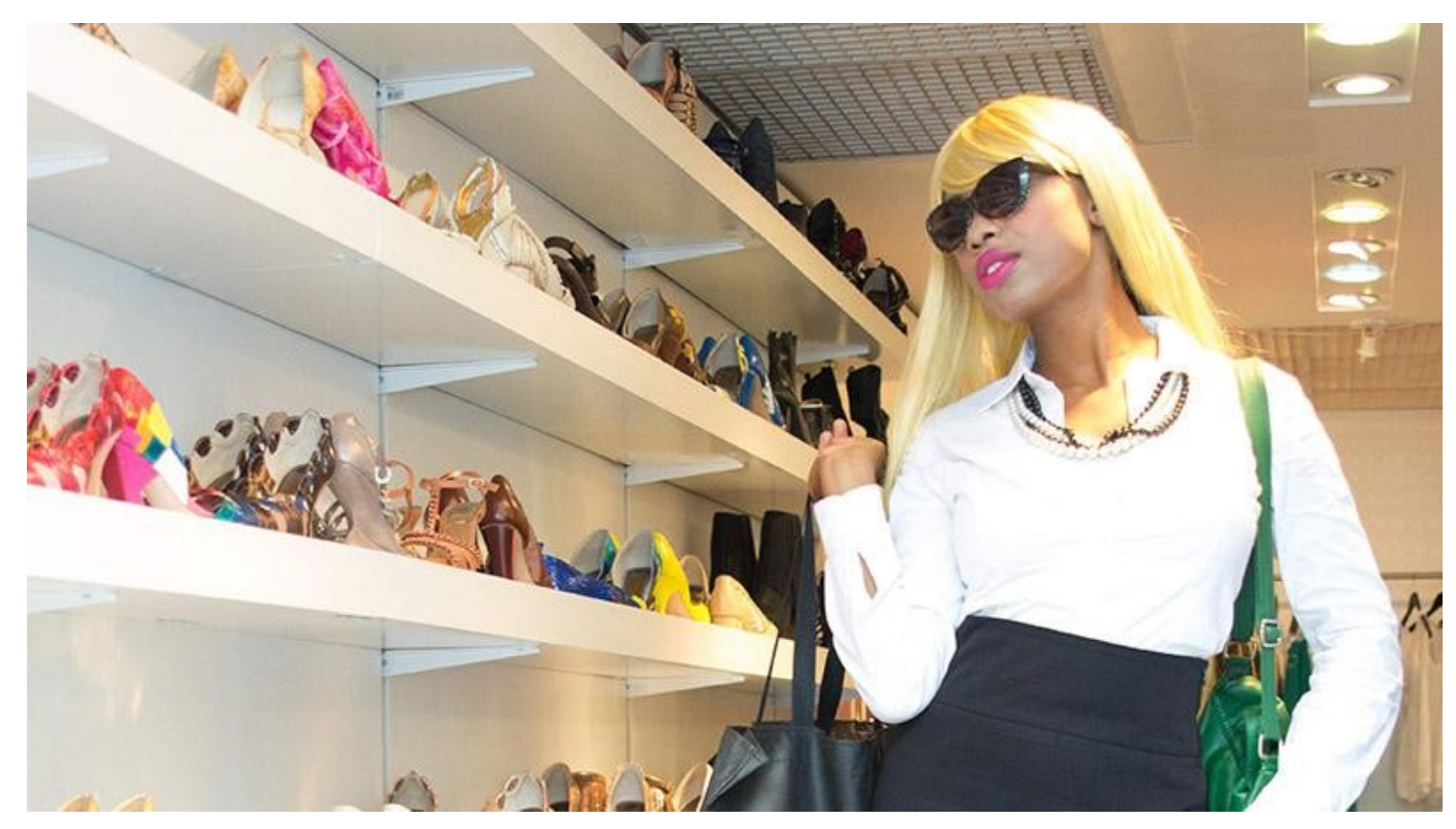

Figura 3: "White Face and Blonde Hair", realizada na Rua Oscar Freire (2012). Foto: Crioulla Oliveira

A performance revela como os padrões de beleza que vigoram no Brasil ainda são extremamente eurocêntricos e excludentes estruturando processos contínuos de violência contra às mulheres não brancas e que não estão dentro de um padrão dominante de beleza branca. Concordarmos com os argumentos de Sovik quando evidencia que no Brasil, "ser branco exige pele clara, feições europeias, cabelo liso; ser branco no Brasil é uma função social e implica 
desempenhar um papel que carrega em si uma certa autoridade ou respeito automático, permitindo trânsito, eliminando barreiras. Ser branco não exclui ter sangue negro” (SOVIK, 2004 p. 366).

A performance de Felinto exemplifica e torna visível as palavras de Otávio Frias ao dizer que a "presença maciça de loiras no imaginário da mídia e do showbiz não é fenômeno tão frívolo, nem tão gratuito. (...) Basta folhear as revistas de ostentação da riqueza e do ócio para verificar o avanço da ‘loirização’ como etapa superior do ‘embranquecimento’” (FRIAS, 09 Dez. 1999, p. 2).

Felinto, enquanto corpo subalternizado, foi falar a respeito da subalternidade invertendo a lógica: o oprimido fala do opressor, o negro fala do branco. E esta opção de Felinto que afronta a opressão, não apenas falar sobre a opressão ao enfocar o subalternizado, e sim uma estética que fala sobre o opressor e das estratégias de manutenção do racismo brasileiro. Ela rompe a noção de invisibilidade, neutralidade, normatividade e silêncio que confere ao branco enquanto indivíduo ou grupo como não marcado, nomeado, racializado, colocando a identidade do sujeito branco em cheque quando Felinto se auto representar como branca para problematizar o papel desta pertença étnico-racial enquanto opressora desse sistema racista e excludente vigente na sociedade brasileira. Questão apontada por Maria Aparecida Bento quando destaca que

o silêncio, a omissão, a distorção do lugar do branco na situação das desigualdades raciais no Brasil têm um forte componente narcísico, de autopreservação, porque vem acompanhado de um pesado investimento na colocação desse grupo como grupo de referência da condição humana. Quando precisam mostrar uma família, um jovem ou uma criança, todos os meios de comunicação social brasileiros usam quase que exclusivamente o modelo branco (BENTO, 2002, p.30).

Cardoso (2008) reforça que investigar e analisar a identidade racial branca é problematizar aquele que numa relação opressor/oprimido exerce o papel de opressor, ou por outras palavras, o lugar do branco numa situação de desigualdade racial.

Portanto, a performance de Felinto, responde e desobedece aos padrões racistas impostos como “universais”, alimentando a produção de uma contra-narrativa negra que é, em si mesmo, um posicionamento que é estético/político de enfrentamento aos imaginários que historicamente aprisionaram o negro em estereótipos e imagens negativas que impactam indelevelmente na personalidade e na autoestima e autoimagem das mulheres que não se encaixam no padrão de beleza propagado como melhor, normal, bonito. É assim que Felinto lança novas perspectivas estéticas para que as tradições racistas deixem de ser perpetuadas na sociedade brasileira. 


\section{REFERÊNCIAS BIBLIOGRÁFICAS}

BENTO, Maria Aparecida Silva. Pactos Narcísicos no Racismo: branquitude e poder nas organizações empresariais e no poder público. Instituto de Psicologia da Universidade de São Paulo. Departamento de Psicologia da Aprendizagem, do Desenvolvimento e da Personalidade. 2002.

BERTH, Joice. O que é empoderamento?. Belo Horizonte (MG): Letramento, 2018.

CARDOSO, Lourenço. O branco ante a rebeldia do desejo: um estudo sobre a branquitude no Brasil. 290 f. Tese (Doutorado) - Universidade Estadual Paulista Júlio de Mesquita Filho, Faculdade de Ciências e Letras (Campus de Araraquara), 2014.

CARNEIRO, Sueli. A Construção do outro como não-Ser como fundamento do ser. Tese (Doutorado em Educação) - Universidade de São Paulo, São Paulo, 2005.

CARONE, Iray; BENTO, Maria Aparecida da Silva (Org.). Psicologia social do racismo: estudos sobre branquitude e branqueamento no Brasil. Rio de Janeiro: Editora Vozes, 2002.

COSTA, Jurandir Freire. Violência e Psicanálise. Rio de Janeiro: Edições Graal, 1984.

FAUSTINO, Deivison Mendes. “Por que Fanon? Por que agora? ”: Frantz Fanon e os fanonismos no Brasil / Deivison Mendes Faustino. -- São Carlos: UFSCar, 2015.

FELINTO, Renata. Entrevista com Renata Felinto. Entrevistador: Rodrigo Severo. São Paulo: 2018.

. White face, blonde hair. Videoperformance. São Paulo, 2012. Disponível em: < https://www.youtube.com/watch?v=r1WqvnAhE6Q >. Acesso em: 10 dez 2018.

. Peformar a vida. In: CONDURU, Roberto (Curadoria). Negros indícios performance vídeo fotografia. São Paulo: Espaço Donas Marcianas, 2017.

FRIAS, Otávio. Sociologia das loiras. Jornal Folha de São Paulo. 09 Dez.1999.

MARTINS, Sérgio. A personagem Adelaide do Zorra Total não é humor é Racismo! Disponível em: https://www.geledes.org.br/sergio-martins-a-personagem-adelaide-do-zorra-total-nao-ehumor-e-racismo/. Acesso em: 18/12/2018.

MIRANDA, Jorge Hilton de Assis. Branquitude Invisível- Pessoas brancas e a não percepção dos privilégios: verdade ou hipocrisia? In: MÜLLER, Tânia Mara Pedroso; CARDOSO, Lourenço. Branquitude: estudos sobre a identidade branca no Brasil. Curitiba: Appris, 2017.

MORAIS, Gustavo. Emicida “detona” personagem do programa “Zorra Total”. Cifraclubnews. 02 outubros 2012. Disponível em: https://www.cifraclubnews.com.br/noticias/43829-emicidadetona-personagem-do-programa-zorra-total.html. Acessado em: 18/12/2018.

MOREIRA, Adilson. O que é Racismo Recreativo? Belo Horizonte: Letramento, 2018. 
MÜLLER, Tânia Mara Pedroso; CARDOSO, Lourenço. Branquitude: estudos sobre a identidade branca no Brasil. Curitiba: Appris, 2017.

PIZA, Edith. Porta de vidro: entrada para branquitude. In: CARONE, Iray e BENTO, Maria Aparecida da Silva (org.). Psicologia social do racismo: estudos sobre branquitude e branqueamento no Brasil. Rio de Janeiro: Editora Vozes, 2002.

SCHUCMAN, Lia Vainer. Entre o "encardido”, o "branco” e o “branquíssimo”: raça, hierarquia e poder na construção da branquitude paulistana. Tese (Doutorado em Psicologia) - Universidade São Paulo, São Paulo, 2012.

SILVA, Oslaine. Mostra fotográfica coloca em discussão padrão de beleza. O Imparcial. 27 de fevereiro 2018. Disponível em: http://imparcial.com.br/noticias/mostra-fotografica-coloca-emdiscussao-padrao-de-beleza,18557. Acesso em: 20/12/2018.

SOVIK, Liv (2004). Aqui ninguém é branco: hegemonia branca no Brasil. In V. Ware (Org.), Branquidade, identidade branca e multiculturalismo (V. Ribeiro, trad., pp. 363-386.). Rio de Janeiro: Garamond.

. Por que tenho razão: branquitude, Estudos Culturais e a vontade de verdade acadêmica. Disponível em: https://portalseer.ufba.br/index.php/contemporaneaposcom/article/viewFile/ 3464/2529. Acesso em: 19/12/2018. 